\title{
How to Construct the Ecological Classroom of College English under Network Information Environment
}

\author{
Li Hongbin \\ Foreign Language Department \\ Jilin Business and Technology College \\ Changchun, China \\ 182076127@qq.com
}

\begin{abstract}
Although the current college English teaching has been into the computer network period, teaching modes up richly than before, the classroom ecology imbalance is still serious. Research for this article, from the perspective of foreign language teaching ecology and education computer network environment to start, for the presence of Eco mode absence of College English Teaching Under the current computer network environment problem, Construction of computer networks Ecological Environment College English necessity of classroom teaching mode. Through analysis, aimed at rational exploitation of ecological factors active awareness, change is limited to active, change the offset is harmony, seeking to build and optimization strategies through computer network ecological teaching mode, so that the healthy and benign development programs implemented in Ecological Perspective college English teaching practice.
\end{abstract}

Keywords-Computer network environment; ecological teaching; College English teaching; teaching mode

\section{EDUCATIONAL ECOLOGY THEORY}

"Ecology" is a concept in biological research. As early as 1866 German biologist Haeckel (Haeckel Erast) put forward the concept of ecology. In 1935 the British ecologist A.G.Tansley and put forward the concept of "eco system". In 1962, the United States Carson Rachel "Silent Spring" led to ecological movement, education ecology and living. In 1976, Columbia Teachers College Dean wrence Cremin in "public education" in a book put forward the concept of "ecological education"[1]. He made use of the ecology basic theory and method of to study the phenomenon of education, from basic theory in ecology began penetrate to education and its branches, and gradually formed a new research field. In 1966, American educator Ashby (AshbyE.) in his famous book, Britain, India and Africa University: of ecology of higher education, "a book for the first time put forward and the application of" ecology of higher education "(Higher Educational Ecology) this concept (Zu bin he, 2005). This created a precedent for the study of higher education in the perspective of ecology. With the development of the research on educational ecology, the content and scope of the research is more extensive.

Academia generally considered "educational ecology" theory term by the American scholar Lawrence • Cremin
(Cremin, L.A.) in 1976 in his book "Public Education", a book officially raised. Our education Ecology research started late in the West, and research in Taiwan earlier than the mainland.

Look forward to the 21st century, due to the impact of the changing natural environment and social environment and economic globalization and other factors, attention to ecological issues even more strongly on the quality and efficiency of ecological education is the gradual growth, which are to promote research and education related to ecology increasingly prosperous. The basic theory of education Ecology triggered widespread discussion by scholars over the years, the microscopic theory to practice specializes in teaching science has made much influential research.

Educational ecology is a cross discipline in the two fields of education and ecology, which emerged in the middle of 1970s. It is the product of the application of ecological principles and research methods in education. Specifically, the ecology rules and Mechanism Study on the interactions between life system and environmental system; education is the status and role of education and social influence on education and education in social development; and the ecology of education is education and ecology as the theoretical basis, research methods used in the two discipline and development, according to the basic principle of ecology, especially the ecological system, ecological balance, CO evolutionary principle and mechanism of all kinds of educational phenomena and causes, and grasp the law of education development, a branch of education reveals the development trend of education and the direction of the study (Fan Guorui, 2000:35) [2]. Ecology of education to promote the education is placed in the natural environment, social environment, regulatory environment, study on ecological environment and human physiological and psychological environment in various ecological factors on education and mutual relationship, by exploring the relationship between different levels of education, object and the surrounding ecological environment factors to the benign development of the main body of education ecology to establish a scientific and reasonable ecological environment. It reveals the education ecological structure, ecological education function, principle of ecological education, ecological law of education, education ecology, ecological succession in education, education ecological monitoring and assessment in 
many aspects, and education science and ecology of other branches in contents and methods have intricate cross and contact, mutual complement and promote each other. At present, the theory research of ecology education, very warm, although generally follow the ecological value view, but due to the difference between their researches focus, research purpose and research paradigm is bound to produce certain differences of opinion. American scholars Cremin and others believe that education should be the main body of research, and study the relationship between education and ecological environment. In his book "public education", he pointed out that in the study of educational ecology, the principle and mechanism of ecology should be used to investigate the "education" and the thinking mode of ecology to think about the reality of education. We can regard education as an organic, relatively independent social subsystem, which is closely related to the surrounding ecological environment[3]. Therefore, educational ecology aims to study the mechanism of the interaction and function of education and the role of the ecological environment (such as nature, society, culture and so on). Scholars in Taiwan Fang Binglin in his book the ecological environment and education, "a book is put forward to ecological environment factors as the main body, focuses on the effects of various ecological environment and education and proceeded to build environment of education impact system. Book Education Ecology of Chinese scholars Wu Dingfu, Zhu Wenyu coauthored the book advocates should put the two unified system, starting from the education and the surrounding ecological environment interaction and mutual relations, to the education system as the main research, analysis of the ecological structure and ecological function of the education, at the same time, to the ecological system of education was a crosssectional study and then open area, establish crisscross network system structure, and focuses on the principle reveals the basic law of ecological education. Based on this, the education of the internal structure, ecological distribution and ecological function should become a basic research object of educational ecology; explore all levels of education ecological mechanism is the main process of the subject; a comprehensive study of the relationship between education on the subject, object and various ecological factors in the field of education and analysis the ecological factors of effect on education mechanism is the overall goal of the research. The works of Chinese scholars fan Guorui the education ecology, this research for the study of the subject to good at study, deal with complex and changeable environment of education, explore educational environment and ecological factors between the dynamic relationship, by observing the phenomenon, cause analysis to discover the laws of development and seek good methods and approaches to optimizing changing educational environment. To sum up, the education ecology is research education and factor and the surrounding ecological environment (including natural, social and normative, physiological, psychological) between the mutual connection and the action of the rule and mechanism of science. In education is thriving today. It emphasizes people to education and their survival environment, dynamic culture and ecological consciousness in the process of education development, to the concept of holism and system research angle of view to analysis and ecological education various constitutive

\section{The Changes of College English TeACHING UndeR THE} COMPUTER NETWORK ENVIRONMENT

Since the beginning of the 1990s, computer network technology in China developed rapidly and quickly into all relevant areas of social life. It can be said that any technology once introduced a specific practice areas, it will indeed cause great changes in the field, and even can bring tremendous completely changed. When modern computer network technology into the traditional foreign language teaching, teaching will bring the first elements of the form and structure of a reset, the reset and will lead to the transmission of information, such as teaching, teaching content and activities combined, the teaching process and Model in the form of a series of design changes, and thus calls for the support of advanced teaching philosophy and comprehensive evaluation standard of Perfection. Given these changes, we must adapt to the times, to promote foreign language courses and computer network technology to integrate well, and explore practical and other effective means of integration required, methods and models[4].After how to attack computer network information technology and foreign language curriculum integration problems and confusion brought about, how the integrated use of a variety of foreign language teaching theory of significance to integrate a comprehensive exposition and demonstration systems integration measures, become the focus of foreign language education research. In a climate of college English teaching reform is in full swing, I believe that these studies are particularly urgent and significant.

From the perspective of educational ecology is concerned, any of the healthy development of the subject teaching has its relatively unique teaching elements, these elements in the longterm teaching practice mutual adaptation, compatibility, and gradually form the external balance and stability of the language teaching environment and inner harmonious development of education ecological system[5]. Traditional foreign language teaching is no exception. However, when the computer network technology has entered the foreign language curriculum, the traditional teaching elements are subject to the new teaching elements (such as a variety of media, network The impact of the content, technical methods, etc., which will lead to the restructuring of the teaching structure and the change of teaching arrangements, such as teaching and learning activities Dynamic design, the positioning of the role of teachers and students, the choice of teaching mode. Between the old and new elements of the need for a run in the long-term course of the coexistence of tolerance and imbalance, the imbalance of the traditional foreign language teaching must break the original ecological balance. Imbalance of the teaching system will immediately lead to more new phenomenon of imbalance. From a macro point of view, at this stage of the curriculum The disorder manifested in the integration mainly includes: the teaching idea and the teaching practice, the national education policy and the school The imbalance of the specific situation, the imbalance of technology and application, the new teaching mode and the imbalance of the traditional teaching system, the teaching process And the teaching management of disorders and so on (Chen Jianlin, 2010:193-197). Along with the curriculum integration to develop in depth, each new form of imbalance 
will also appear in the macro and micro fields of teaching, which has a direct impact on the whole the normal operation of the foreign language teaching system has seriously restricted the healthy and orderly development of the modern foreign language teaching in China. The author thinks,

It is necessary for us to carry out all kinds of research, timely and effective intervention and active regulation of these disorders.

\section{CONSTRUCtion OF ECOlOgicAl TEACHING MODEL OF \\ COLLEGE ENGLISH IN COMPUTER NETWORK ENVIRONMENT}

We want to reasonable analysis of the causes of imbalance phenomenon, explore solutions to the imbalance phenomenon countermeasure, and rely solely on traditional teaching theory is difficult to realize. Traditional teaching theory although can well explain the nature of human learning activities, but teaching imbalance phenomenon has on the traditional theory poses a challenge is mainly because the components of the integrated teaching system has changed, the existing teaching system not only relates to two aspects of teaching and learning, also includes such as technology and resources more elements[6]. Therefore, in order to find the causes and Countermeasures of imbalance, make the teaching system restore dynamic harmony, it should be based on the traditional theory of advantage, based on the ecological perspective to reexamine our foreign language teaching, which is based on the principle of ecology and educational ecology theory, investigating the internal relationship between foreign language teaching system structure factors and external environment for development. To explore the characteristics and function of foreign language teaching environment, and the basic rules of its evolution and development, such as goal setting, curriculum design, teaching activities and teaching students to construct the teaching model of state exploration, the domestic research on ecological teaching pattern has made some achievements in the study of macroscopic and microscopic field, combining with teaching practice English in our university, the author selects Jiamusi University as the research object, carries out the empirical research. Through the observation and evaluation of the school under the computer network environment university English teaching development situation and confirm the information technology of the join does lead to disorders and changes of traditional college English teaching, and then puts forward the core problem of the research. Study on the problem of setting, the author conducted a detailed design of the empirical research, from three aspects under the network environment, students, teachers and teaching environment to determine the research variables, by means of questionnaire, interview and classroom observation, comprehensive evaluation of teachers and students about the multimedia classroom and students network solutions based on autonomous learning classroom the teacher summed up, found six classes of the school's traditional English teaching and modern education means in the process of integration: imbalance disorders teaching model and teaching environment imbalance, teaching idea and the role of teachers and students, the imbalance of basic quality of teachers education network imbalance, student information technology and autonomous learning ability, the teaching process and disorders the teaching evaluation imbalance, teaching equipment and management background.

This paper provides a new empirical support for the ecological teaching of College English in the computer network environment in China. The results of the study on the domestic and foreign related research has played a certain complement[7]. Subsequent research also has the very big space, on the one hand, we can try to make up for the deficiencies and limitations, to increase empirical research efforts on the optimal strategy of the conclusion of the study provides further practice of classroom teaching with the inspection and perfect; on the other hand, we can also do more research in the computer network environment, the ecology of College English reform, such as how to strengthen the teachers' information literacy and how to design a more adapted to the needs of students of web-based autonomous learning platform and how to characteristics of the schools College English school-based curriculum construction and development. The study of foreign language teaching in computer network environment from the perspective of educational ecology provides a new opportunity and clear direction for the reform and research of College English Teaching in our country[8]. This is a systematic and durable engineering task, the overall research to go15, need at all levels of education and scientific research workers unremitting efforts continue to explore the road of ecological development in teaching reform, realize the sustainable development of China's College English teaching.

\section{SUMMARY:}

With the gradual advancement of globalization and the rapid development of computer network technology, many aspects of people's lives are being subjected to the strong impact of the network era. Traditional foreign language teaching in the computer network to meet the new environment and opportunities, but also faced with unlimited challenges and challenges. How to guide them to efficient integration of resources, give full play to the advantage of the information age, computer networks to meet the needs of the development of modern education and real integration has become the curriculum of organic composition part, become important issues to promote China's College English teaching from the traditional to the modern transformation, but also constitutes a focus of research in the current domestic and foreign language teaching reform.

\section{REFERENCES.}

[1] Beane, J. A. Curriculum Integration: Designing the Core of Democratic Education [M]. Teachers College Press, Columbia University, 1997.

[2] Burden, P. R. \& Byrd, D. M. Methods for Effective Teaching [M]. The United States of America: Allyn \& Bacon, 1999.

[3] Koschmann, T. CSCL: Theory and Practice of an Emerging Paradigm [M]. Mahwah, New Jersey: Lawrence Erlbaum Associates, Publishers, 1996.

[4] Daniel, John, From the Triangle to the Pentagon: Open Universities in the 21th Century [R]. The 18th Asian Association of Open Universities Annual Conference. Shanghai, 2004(11).

[5] Dillendourg, P. Collaborative Learning: Cognitive and Computational Approaches [M]. Oxford: Pergamum Press, 1999. 
[6] Gardner, D. and Miller, L. Establishing Self-Access --- From Theory to Practice $[\mathrm{M}]$. Shanghai: Shanghai Foreign Language Education Press, 2002.

[7] Levy, M. and Stockwell, G. CALL Dimensions: Options and Issues in Computer-Assisted language Learning $[\mathrm{M}]$. Lawrence Erlbaum Associates, Inc, 2006.
[8] Rogers, Y. New Theoretical Approaches for Human-Computer Interaction[J]. Annual Review of Information, Science and Technology, 2004. 